\title{
Australian Social Work Research on Ageing and Aged Care: A Scoping Review
}

\author{
Mark Hughes, Christine Bigby \& Clare Tilbury ${ }^{1}$
}

\begin{abstract}
Summary: Little is known about the quantity, nature and range of Australian social work research on ageing and aged care. This scoping review involved a comprehensive search of seven online bibliographic databases. The review identified 108 peer-reviewed journal articles, published between January 2007 and June 2014, that reported Australian social work research on ageing and aged care.
\end{abstract}

Findings: The average number of authors per paper was 2.10 with most social work researchers co-authoring papers with non-social workers. The main topics of research focus were health and rehabilitation, elder abuse, asset management, community services and caregiving, housing and residential aged care, and ageing with an intellectual disability. The findings highlight the contribution social work researchers make to multidisciplinary gerontological research, and to understanding the lived experiences of older people and the provision of services. However, they also point to the relative paucity of research focusing on direct social work practice with older people, and the little evidence of the participation of older people and carers in the design and delivery of research.

Applications: The findings indicate the need for capacity-building strategies, such as developing networks of Australian social work researchers on ageing and aged care, to improve research outputs in this area.

Australian social workers are employed in a diverse range of organisations that provide services to older people. For example, social workers have long been employed in aged care assessment teams, which assess older people's living circumstances and determine eligibility to receive government-subsidised aged care services such as home-based support and residential care. Many social workers are employed in non-age specific settings that provide services to older people, including community and mental health services, disability services, housing services, private practice, and Centrelink (Australia's benefit agency). Social workers are also employed in policy, research and advocacy roles related to ageing and associated issues both within and outside of government. Although relatively few social workers are employed in residential aged care, unlike in the United States (Simons, Shepherd, \& Munn, 2008), the many social workers in hospitals play a key role in facilitating older people's access to acute, transitional and long-term care.

The significance of social work practice with older people is underlined by the impacts of population ageing and the challenges of a changing health and human services sector. In Australia, the population aged 65 years and over is expected to increase from $14 \%$ of the total population in 2012 up to $19.4 \%$ in 2030, and then up to $24.5 \%$ by 2060 (Australian Bureau of Statistics [ABS], 2013). This will result in greater rates of age-related chronic conditions such as dementia, diabetes and cardio-vascular disease. A major policy concern is the older age dependency ratio (the proportion of people aged 65 years and over compared to the working population of those aged 15 to 64), which is set to increase from $20 \%$ in 2007 to $42 \%$ in 2056 (ABS, 2009). Therefore, while there are benefits arising from population ageing, such as increased social and intellectual capital (Australian Institute of Health and Welfare [AIHW], 2013), there are questions about the nation's capacity to generate the resources required to

\footnotetext{
${ }^{1}$ Postprint of Hughes, M., Bigby, C., \& Tilbury, C. (2016). Australian social work research on ageing and aged care: A scoping review. Journal of Social Work. doi: 10.1177/1468017316654346
} 
sustain an increasingly older population. This demographic imperative has resulted in national reforms designed to reduce the burden of disease towards the end of life, increase the economic productivity of the older population, and reduce health (particularly pharmaceutical) and social expenditure (Hughes \& Heycox, 2010). Australia is also part-way through the implementation of an aged care reform programme that will see the roll out of consumer directed care in the delivery of community aged care (AIHW, 2013), with the possibility that this approach will be extended to residential aged care (McStay, 2015).

These changes will require a skilled social work workforce: able to work with the complexities of older people's lives and relationships, and mobilise resources to enhance wellbeing in the context of constrained public expenditure (Hughes \& Heycox, 2010). However, as in other countries, there remain questions about the interest and capacity of social workers to engage effectively with older people. This is most noticeable in research on student interest in ageing. For example, in a study of 1042 social work students in the United States, England and Australia, just 5.4\% indicated an interest in gerontology (Chonody \& Wang, 2014). In an earlier Australian study, the average score on a 10-point interest in working with older people scale was just 5.13 (with 10 representing the greatest interest), and the average score on a 12-item ageing knowledge instrument was 8.5 (71\%) (Hughes \& Heycox, 2006). While limited interest and knowledge may reflect ageist attitudes, they also suggest a lack of imagination about the diverse areas and methods of practice relevant to social work with older people. These can range from psychosocial interventions in the provision of palliative care in residential facilities (Robertson, 2008) to facilitation of age-friendly communities in urban areas (Ozanne, Biggs, \& Kurowski, 2014). McCormack (2008) and Duffy and Healy (2011) have pointed to the complexity and dynamic nature of social work with older people in the hospital setting, detailing the role of multidisciplinary teamwork, comprehensive biopsychosocial assessments, family conferences, counselling interventions, and advocacy as all part of everyday practice.

The challenges, complexity, and richness of social work practice with older people suggest a fertile ground for social work research on ageing and aged care. Yet questions have been raised internationally about whether this potential is being realised. In the United States, there are concerns that the number of active gerontological social work researchers is disproportionately small compared to the number of social workers employed in the aged care sector (Simons et al., 2008, Mehrotra, Townsend, \& Berkman, 2014). This has led to strategies such as training programmes to build postgraduate research expertise in social work gerontology (Mehrotra et al., 2014), alignment of social work research capacity with national health research agendas (Raveis, Gardner, Berkman, \& Harootyan, 2010), and facilitation of universitycommunity partnerships to ensure that social work research is relevant and meaningful to older clients and practitioners (Chapin, Sellon, \& Wendel-Hummell, 2015). In the UK, concerns have been raised about the coverage of gerontological research in social work journals, and calls have been made for more research on the effectiveness of social work interventions with older people (Richards et al., 2014). Although Carey (2016, p. 352) challenged the promotion of 'gerontological social work into fulfilling science-led and health care oriented objectives and interventions'. While we employ the term 'gerontological social work' in this paper due to its ubiquity (particularly in the United States), we recognise that this is a socially constructed concept that may reflect dominant discourses, such as the biomedicalisation of ageing.

There are also questions about the degree to which older people and carers are actively engaged in the research enterprise, aside from solely being research participants (D'Cruz \& Gillingham, 2016). According to Fisher (2002) the pursuit of an equitable society relies on research participants being involved in activities such as problem formulation, research design and project implementation. Such involvement is far from straightforward, with diverse ideological influences - ranging from neoliberal market-oriented values to humanistic democratic principles (Carey, 2010) - influencing the nature and scale of the involvement. Nevertheless Carey argues that these influences coalesce in political realities, and what is 
needed is counter-hegemonic strategies such as attention to the long-term impact of research on participants, promotion of knowledge production by service users and challenging the impact of managerial, organisational and professional agendas in research.

In Australia there is an even greater gap in understanding about social work research on ageing and aged care. It is unclear how much research is being conducted in this area, as well as its nature and range. While there is scope for the transfer of knowledge from other countries to the Australian context, there is also a need for world-class Australian research in order to address local issues, and to increase the effectiveness and productivity of the Australian health and human services industries. A better understanding is also required of the extent to which older people and carers are involved in research processes beyond the typical research participant role. Thus, the purpose of the study reported on in this paper was to investigate the quantity, nature, and range of Australian social work research on ageing and aged care. The method employed to facilitate this investigation was a scoping review of the literature.

\section{Method}

A scoping review provides a broad map of a research literature, and while often a pre-cursor to a systematic review it can also be a research outcome in itself (Armstrong, Hall, Doyle, \& Waters, 2011). Whereas a systematic review focuses on a very specific research question, in a scoping review the question is typically quite broad and aimed at identifying the parameters of and gaps in the literature (Armstrong et al., 2011). It can accommodate a heterogeneous literature as well as diverse methodologies (Pham et al., 2014). In contrast to a systematic review, a scoping review does not usually involve an assessment of the quality of the methodologies employed in specific studies, nor does it involve a meta-analysis of research findings (Pham et al., 2014). Despite these differences, many of the techniques employed in a systematic review can also be deployed in a scoping review, including a rigorous and transparent approach to searching for, selecting and analysing the literature as it relates to the research question (Pham et al., 2014). As Pham et al. (2014) argued, it is important to stress that scoping reviews are not less rigorous than systematic reviews; rather they have a different purpose and focus on different research questions.

Scoping reviews are a relatively new approach and as yet there is no clearly delineated methodology, although use of Arksey and O'Malley's (2005) approach is widely advocated (Pham et al., 2014). This involves: specifying the research question; identifying relevant studies; selecting the studies; charting or mapping the data according to certain criteria; and collating, summarising and reporting the results (Arksey \& O'Malley, 2005, p. 22). The PRISMA method of conducting systematic reviews (Moher, Liberati, Tetzlaff, Altman, \& The PRISMA Group, 2009) can also be drawn upon to inform some aspects of the design and reporting of scoping reviews, particularly the use of a flow diagram to illustrate the process of study selection (Pham et al., 2014). Both of these approaches informed the way our scoping review was carried out, although the unit of analysis in this review was journal articles reporting on research, rather than the research studies themselves. (Thus, the review may have included multiple publications reporting on the same piece of research.)

\section{Research question}

What is the quantity, nature, and range of recent social work research on ageing and aged care conducted in Australia?

\section{Inclusion and exclusion}


A series of inclusion and exclusion criteria was used to ensure that the publications selected related to the research question. The focus of this study was on journal articles published in English-language, peer-reviewed journals. The articles had to be available online, to be identifiable through an electronic database, and to have been published between January 2007 and June 2014. The beginning year of 2007 was selected as this accorded with the election of a new national government (the Rudd Labor Government), which had announced a new framework for assessing the quantity and quality of Australian research. The end date was at the time when the search commenced. Books, book chapters, published reports, editorials, letters to the editor, commentaries, news or magazine articles, and grey literature (e.g., unpublished reports) were excluded.

To be included, the articles needed to report empirical research, which was defined as the systematic use of a research methodology to investigate a topic and generate knowledge in the form of research findings or results. This excluded theoretical articles, policy discussion papers, and reflective pieces. It also excluded essays and literature reviews, except where the review employed a specific methodology in a systematic way. Thus systematic reviews, scoping reviews, critical interpretive reviews and some narrative reviews could be included.

The scoping review was restricted to Australian research on ageing and aged care. This was operationalised as the article having been written by at least one Australian author (i.e., whose byline indicated that they resided in or were employed in Australia) or by non-Australian authors whose research reported Australian content. This included comparative studies where Australian content comprised only one part of the findings reported. The focus on ageing and aged care was defined as research that related to the process of growing old, the experiences of those typically categorised as older, and the delivery of services or other resources (e.g., informal care) to older people. As outlined in more detail below, a series of key terms relating to ageing and aged care was used to restrict the sample of publications generated.

The other inclusion criterion was that the articles needed to report social work research. There are different ways in which social work research can be defined and operationalised. In the Australian context, the Excellence in Research for Australia exercise utilises a specific social work field of research code, however, research conducted by social workers is also counted in other codes, such as policy and administration. Social work research can also be defined as any research that meets the purpose of social work, such as research that informs decisions impacting on service users and carers, and informs policy and how services are delivered (Orme, 2006). If the latter approach was followed then it is conceivable that people who are not qualified social workers may produce social work research. Alternatively, social work research can be defined as the research carried out by social workers, that is, people with social work qualifications. With the latter, it is possible that research not directly relating to social work would be included in this definition (e.g., if social workers were involved in a project evaluating medical training). Despite this possible limitation, for the purposes of this study, we defined social work research as the research carried out by qualified social workers. This was determined by identifying that at least one of the authors had a social work qualification. Where this could not be determined by the author's byline, information was sought from their employer's website.

\section{Search strategy}

Two search strategies were employed for this scoping review, both of which relied on searching electronic databases (see Figure 1). In the first strategy, the following seven databases were searched by key terms related to the topic: Cinahl, Scopus, Current Contents, PsychInfo, Social Service Abstracts, Medline and Sociological Abstracts. Combinations of the following terms with Boolean phrases were employed: Austral*, social work, human services, social care, community services, elder*, ageing, aging, senior, older, geront*, aged care, old age, old, aged, 
age, dementia, residential care, community care, elder abuse. This strategy produced 17,494 publications. In order to generate a more targeted list, all items were imported into Endnote and searched according to the term "social work" in any field. Following removal of duplicate papers, a total of 2787 publications were available for assessment.

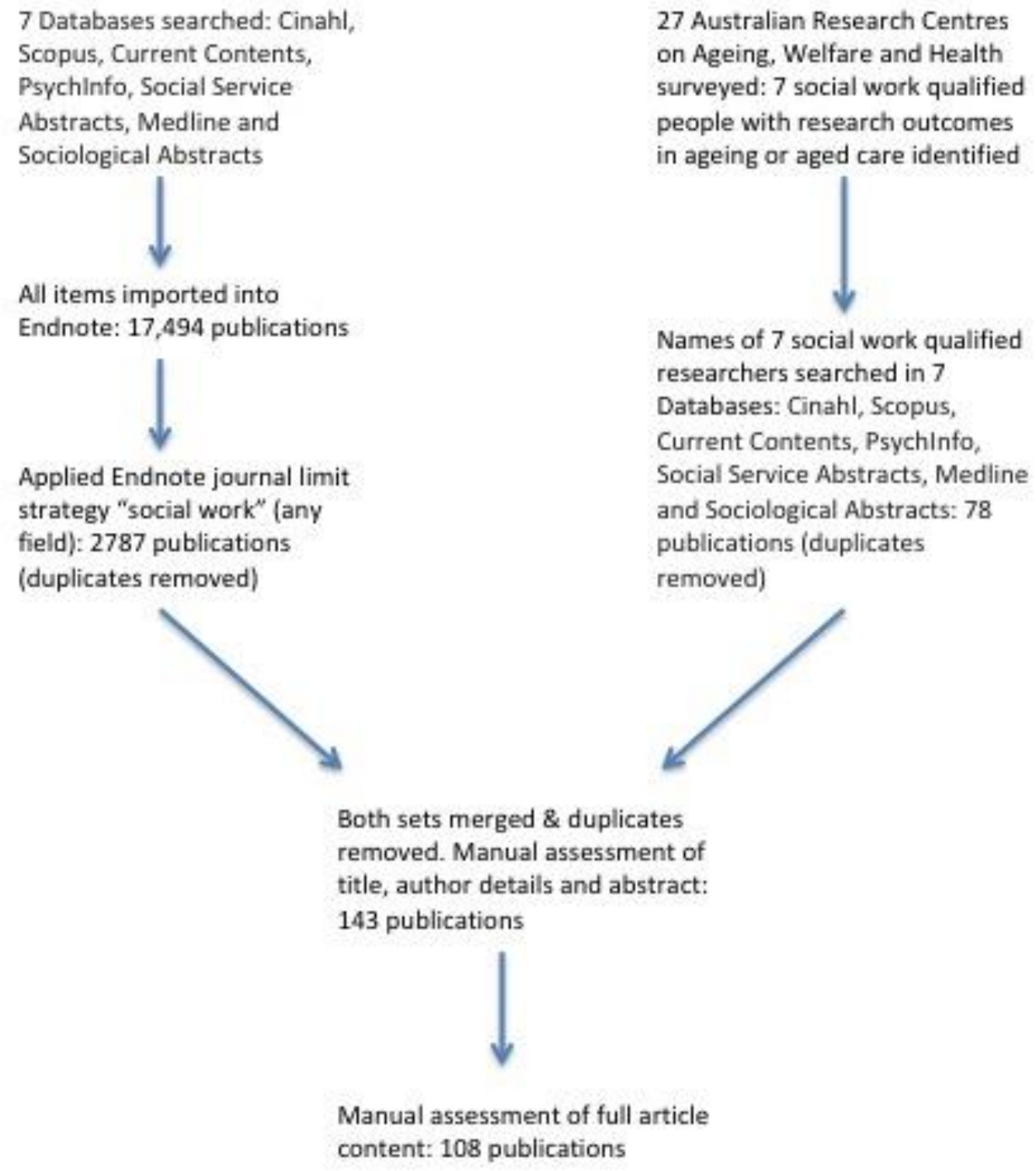

Figure 1. Flow chart of searching and assessment process

A preliminary check of this set of publications revealed that while all social work academics employed in Australian Schools of Social Work (or their equivalent) who had published on ageing and aged care had been included, there were some social work qualified researchers employed by research centres or institutes who were not captured by the search. Thus, a second search strategy was employed. This involved accessing online staff lists of 27 Australian research institutes or centres that focus on ageing, welfare or health, and identifying social work researchers with publications relating to ageing or aged care. Seven people were identified in this way. The names of these researchers were searched for in the same seven databases reported above, resulting in the identification of 78 additional publications that were suitable for assessment. 
Both sets of publications were then combined $(2787+78)$ and, after duplicates were removed, publications were assessed based on the title, author details and abstract of the paper.

Assessment involved ensuring that the paper had at least one social work qualified author, that at least one author was based in Australia or that the paper reported on Australian research, that the paper met the definition of research, and that the research related to ageing or aged care. The result was a set of 143 publications that either met the above criteria or it was not possible to discern, based on the information, that they met the criteria. These latter publications were then subjected to a manual assessment of the full article and either included or excluded on the basis of the key criteria. The final sample of publications totaled 108.

\section{Analysis}

The approach outlined by Arksey and O'Malley (2005) involves analysing the literature according to certain criteria related to the research question. For the purposes of this study, the following criteria related to the quantity, nature and range of social work research on ageing and aged care were examined: number of authors (including number of social work authors); number of publications per author; year of publication; journals most frequently published in; main topic of research focus; methods employed; unit of analysis; involvement of older people and carers; main funding source. The data were analysed through basic univariate techniques of frequency, percentage, and mean calculations.

\section{Findings}

A total of 227 people were identified as authors of the 108 selected papers: an average of 2.10 authors per paper. Of these 227, 67 (29.5\%) were qualified social workers. Thus, while the inclusion criteria meant that there was at least one social work author per paper, the vast majority of papers also had non-social work qualified people as co-authors. Indeed there were only 11 papers $(10.2 \%)$ that were sole authored by social workers. The majority of social work authors $(65.7 \%)$ published only one paper related to ageing and aged care in Australia between January 2007 and June 2014 (Table 1). In terms of number of publications, there were two outliers: one person (Dow) authored 25 publications and another (Haralambous) authored 16 publications that met the inclusion criteria. Both these authors are employed by the National Ageing Research Institute. The other most prolific Australian social work authors on ageing and aged care were: Tilse from the University of Queensland ( 9 publications); Bigby from La Trobe University (8 publications); Biggs from the Brotherhood of St Laurence and the University of Melbourne (8 publications); Wilson from the University of Queensland (7 publications); Chonody from the University of South Australia (5 publications); Rosenman from the University of Queensland and Victoria University (5 publications); and Hughes from Southern Cross University (5 publications).

Table 1. Number of publications by author

\begin{tabular}{lcccc}
\hline Number of publications & \multicolumn{2}{c}{ All authors } & \multicolumn{2}{c}{ Social work authors } \\
\hline & Frequency & Percentage & Frequency & Percentage \\
1 publication by author & 151 & 66.5 & 44 & 65.7 \\
2 publications by author & 35 & 15.4 & 10 & 14.9 \\
3 to 5 publications by author & 31 & 13.4 & 7 & 10.5 \\
6 or more by author & $10 \#$ & 4.4 & $6 \sim$ & 8.9 \\
TOTAL & 227 & 100.0 & 67 & 100.0 \\
\hline
\end{tabular}

\# includes 25 papers $=1 ; 17$ papers $=1 ; 16$ papers $=2$

$\sim$ includes 25 papers $=1 ; 16$ papers $=1$ 
The average number of publications per year that met the inclusion criteria was 14.4 (taking into account the six months of 2014), ranging from seven in 2010 to 25 in 2013 (Table 2). Given that there were 15 publications in the first six months in 2014 it is likely that the total number of publications in that year would have exceeded 25 . While the number of social work research publications on ageing and aged care has been relatively stable across the seven years, the results from 2013 and 2014 may indicate the start of an upward trend.

Table 2. Year of publication (2007- June, 2014)

\begin{tabular}{lcc}
\hline Year of publication & Frequency & Percentage \\
\hline 2007 & 14 & 13.0 \\
2008 & 13 & 12.0 \\
2009 & 11 & 10.2 \\
2010 & 7 & 6.5 \\
2011 & 12 & 11.1 \\
2012 & 11 & 10.2 \\
2013 & 25 & 23.1 \\
2014 (to June) & 15 & 13.9 \\
TOTAL & 108 & 100 \\
\hline
\end{tabular}

Australian social work research publications on ageing and aged care were published across 53 journals, although nearly half of all publications $(48.1 \% ; 52 / 108)$ were in only seven journals (Table 3). The greatest proportion of papers was published in the Australasian Journal on Ageing $(13.0 \%$; 14/108), while the next most common publication outlets were Australian Social Work $(9.3 \% ; 10 / 108)$ and Ageing and Society $(8.3 \%$; 9/108). Of the 53 journals authors published in, the majority $(56.6 \% ; 30 / 53)$ were health journals, followed by social work journals $(15.1 \% ; 8 / 53)$, generic ageing journals $(9.4 \% ; 5 / 53)$ and disability journals $(9.4 \% ; 5 / 53)$. Interestingly, of the 53 journals, 17 (32.1\%) were specifically in other discipline areas, such as nursing, medicine, psychiatry, and occupational therapy. Of the 53 journals, only six $(11.3 \%)$ were Australian, although of the 108 articles, 32 (29.6\%) were published in these six journals.

Table 3. Top journals

\begin{tabular}{lcc}
\hline Journal & Frequency & Percentage \\
\hline Australasian Journal on Ageing* & 14 & 13.0 \\
Australian Social Work* & 10 & 9.3 \\
Ageing and Society & 9 & 8.3 \\
International Psychogeriatrics & 5 & 4.6 \\
Australian Health Review* & 5 & 4.6 \\
Journal of Intellectual and Developmental Disability & 5 & 4.6 \\
Social Work in Health Care & 4 & 3.7 \\
TOTAL & $52 / 108$ & 48.1 \\
\hline
\end{tabular}

* Australian journals

A focus on health was also reflected in the main research topic of the articles that met the inclusion criteria, with $24.1 \%$ of the 108 articles addressing health or rehabilitation issues (Table 4). Many of the articles published by the social work researchers (Dow and Haralambous) from the National Ageing Research Institute had such a focus. Some of the issues addressed in these publications included healthy ageing, mobility and falls prevention, dementia, and rehabilitation in rural areas. The next main topic of research was elder abuse, including financial abuse and related asset management issues $(15.7 \%$; 17/108). A number of these papers was generated by the Assets and Ageing Research Program at the University of Queensland, which included authors: Tilse, Wilson and Rosenman. Thirteen percent (14/108) of articles reflected a main 
focus on community services, family caregiving and social networks. Housing and residential aged care accounted for $10.2 \%$ (11/108) of the publications, while education was the focus of 9.3\% (10/108). A further 10 articles $(9.3 \%)$ focused on ageing with an intellectual disability, with the research from the Living with Disability Research Centre at La Trobe University (including Bigby) being prominent.

Table 4. Main topic of research focus

\begin{tabular}{lcc}
\hline Topic & Frequency & Percentage \\
\hline Health/rehabilitation & 26 & 24.1 \\
Elder abuse/financial abuse/asset management & 17 & 15.7 \\
Community services/caregiving/social networks & 14 & 13.0 \\
Housing/residential aged care & 11 & 10.2 \\
Education & 10 & 9.3 \\
Ageing with an intellectual disability & 10 & 9.3 \\
CALD services/support & 9 & 8.3 \\
LGBTI ageing & 6 & 5.6 \\
Other* & 5 & 4.6 \\
TOTAL & 108 & 100 \\
\hline
\end{tabular}

*Other includes counseling, therapy, prisoners, consumer needs, and demography

In addition to categorising the articles according to main research topic, we also examined the extent to which they were focused on social work specifically. Of the 108 articles, $26(24.1 \%)$ had a section discussing social work specifically or included social work participants in the study. In half of these papers (13) social work was one part of a focus on multiple disciplines or multi-disciplinary teams (e.g., aged care assessment teams). Thus in only 13 of the 108 articles (12.0\%) was social work the named focus of the article. In five of these articles, the focus was on interest in or attitudes towards older people of social work students, academics or practitioners. In four articles the focus was on social work practice relating to elder abuse or domestic squalor. Three articles focused on social work practice in hospitals, including the use of assessment tools, and one article focused on social work interventions to support long-term care decision-making as part of a systematic review.

The studies reported on in the 108 articles were classified in terms of their method. Forty-seven papers (43.5\%) were classified as qualitative, and included in-depth interviews, focus groups, ethnography, action research and case studies (Table 5). Quantitative research accounted for $24.1 \%$ (26/108) of the methods, and included surveys, records-based research, and secondary analysis of existing datasets. A considerable proportion $(22.2 \% ; 24 / 108)$ involved mixed quantitative and qualitative methods either in the form of surveys with both open and closed questions, or by using different methods of data collection to investigate the issue (e.g., conducting both surveys and focus groups). Eleven papers (10.2\%) reported systematic reviews of the research literature, following a specific method, such as PRISMA.

Table 5. Methods

\begin{tabular}{lcc}
\hline Method & Frequency & Percentage \\
\hline Qualitative & 47 & 43.5 \\
Quantitative & 26 & 24.1 \\
Mixed method & 24 & 22.2 \\
Systematic review & 11 & 10.2 \\
TOTAL & 108 & 100 \\
\hline
\end{tabular}

There was a range of participants or units of analysis in the studies reported on in the 108 publications (Table 6). The majority of articles $(29.6 \% ; 32 / 108)$ reported research involving 
multiple participants, as might be expected given the number of mixed method studies. In total, older people were reported to be research participants in 53 articles (49.1\%), and they were the sole participant group in 30 articles $(27.8 \%)$. Thirty-seven papers $(34.3 \%)$ involved staff or service providers (including social workers and other professionals) as participants in the research. In 14 articles (13.0\%) they were the only research participant group. In 25 articles (23.1\%) family members or carers were participants in the research; they were the sole focus in 5 articles (4.6\%). Other units of analysis/participants included literature (for systematic reviews), client or organisational records, students and academics, and the general public.

Only 16 articles $(14.8 \%)$ reported the involvement of older people or carers (e.g., as service users) in activities additional to what might be considered usual for research participants. In 8 articles (7.4\%) older people or carers were involved in the design of the study, although the extent to which this illustrated a degree of service user control over the research process varied considerably. Approaches to involvement in research design and implementation included:

- consultation about a survey instrument or other aspects of the research methodology (4 articles);

- development of research recommendations following a systematic review (1 article);

- active participation in designing a research instrument (2 articles);

- a cooperative inquiry method where older people and carers acted as co-researchers alongside service providers and academic staff ( 1 article).

In 6 articles $(5.6 \%)$ the research involved a process of respondent validation or member checking with older people or carer participants feeding back on the accuracy of an interview transcript or summary of research findings. In 8 articles (7.4\%) mention was made of a project reference group or similar (e.g., expert advisory panel, critical reference group) but in only 2 of these articles was it specified that older people or carers, or members of their representative or advocacy organisations, were involved in this group. In 5 articles (4.6\%) there was evidence of extensive support provided to research participants either by the researchers or by support or advocacy organisations. In each of these articles the research involved people with intellectual disabilities participating in a research process over an extended time period (e.g., multiple interviews over one year).

Table 6. Unit of analysis or participants for empirical studies

\begin{tabular}{lcc}
\hline Unit of analysis & Frequency & Percentage \\
\hline Mixed sample (2 or more participant types) & 32 & 29.6 \\
Older people & 30 & 27.8 \\
Practitioners/service providers/staff & 14 & 13.0 \\
Literature (systematic review) & 11 & 10.2 \\
Records/administrative data/other documents & 6 & 5.6 \\
Informal carers & 5 & 4.6 \\
Other adults/general public & 4 & 3.7 \\
Organisation (ethnography or audit) & 3 & 2.8 \\
Academics & 2 & 1.9 \\
Students & 1 & 0.9 \\
TOTAL & 108 & 100 \\
\hline
\end{tabular}

The articles were also categorised in terms of main funding source, where that information was possible to discern (Table 7). Nineteen articles (17.6\%) identified that they primarily relied on funding from a state or federal government department. In terms of the major nationally competitive research grants, 15 papers (13.9\%) reported that the research was funded by the Australian Research Council (ARC), 2 were funded through an Australian Postgraduate 
Award (APA), and 1 was funded by the National Health and Medical Research Council (NHMRC). With respect to the ARC grants, in only one case was the grant an ARC Discovery grant; the remainder was ARC Linkage grants, which involve partnerships between research institutions and industry- or community-based organisations. In 12 articles (11.1\%) the funding was reported to have come from a charitable trust or private donation (e.g., the Clifford Craig Medical Research Trust), while in 10 cases (9.3\%) the funding was from a university either in cash or in-kind. In six papers $(5.6 \%)$ the funding was reported to come from a non-government organisation (e.g., Beyond Blue). In the case of 43 articles (39.8\%) the funding source was not stated. It seems likely that a substantial number of these would have involved in-kind support from the authors' employer or would have been self-funded.

Table 7. Main funding source

\begin{tabular}{lcc}
\hline Funding source & Frequency & Percentage \\
\hline Government - state or federal & 19 & 17.6 \\
Australian Research Council (ARC) & 15 & 13.9 \\
Charitable trust/private donation & 12 & 11.1 \\
University grant or in-kind & 10 & 9.3 \\
NGO & 6 & 5.6 \\
Australian Postgraduate Award (APA) & 2 & 1.9 \\
NHMRC & 1 & 0.9 \\
Not stated & 43 & 39.8 \\
TOTAL & 108 & 100.0 \\
\hline
\end{tabular}

\section{Discussion}

In the United States, Simons et al. (2008) suggested that social work researchers are failing to meet the needs of older service users and social workers in aged care. Is the same true in Australia? On the basis of this scoping review, it is appears that the amount of social work research on ageing and aged care is relatively low, with an annual average of 14.4 papers published over 7.5 years. Of the 108 articles published across this time period, just $12.0 \%$ (13 articles) named social work specifically as their main focus. There were few evaluations of direct social work practice with older people and only one systematic review that addressed a social work intervention. There was also limited evidence of the involvement of older service users and carers in research design and delivery.

But social work researchers are contributing to the needs of older clients and social workers working with older people in other ways. In this scoping review, 67 social workers were identified as publishing research on ageing and aged care between January 2007 and June 2014. The vast majority of these people collaborated with non-social work researchers in investigating issues related to health and rehabilitation, physical and intellectual disability, dementia, elder abuse, asset management, family caregiving, community services, LGBTI ageing, CALD ageing, and housing and residential aged care. Much of this research was practice- and service delivery-oriented, even if its named focus was not specifically social work. However, the preponderance of social workers contributing to health research does raise the question as to whether 'gerontological social work' is becoming co-opted by health and science agendas (Carey, 2016).

It was also notable that nearly half of the articles included in this study reported on research that included older people as participants. Thus this research most likely would have assisted in building the stock of knowledge (e.g., about residential aged care) that can assist in improving the wellbeing and rights of older people, as well as supporting the improvement of practice in other disciplines (such as nursing). It may be that social work researchers - drawing on social work values, knowledge and skills - would have added something unique to these 
studies, that might not otherwise have been present. If a broad definition of social work research is adopted - one that is about enhancing understanding of social problems, improving practice in the human services, developing equitable social policy and empowering service users and carers - then most of the articles reported on in this study would have been engaged in such an enterprise.

There were some other qualities of Australian social work research on ageing and aged care that emerged from this scoping review that are important to reflect on. Social workers employed a diversity of methods in their research although the greatest proportion of papers $(43.5 \%)$ reported qualitative research. While only one systematic review on social work interventions was identified, 11 articles in total reported systematic reviews. This is a valuable outcome as systematic reviews assist in aggregating research, identifying the strengths and weaknesses of specific interventions, and developing research agendas. It was also notable that Australian social work researchers on ageing and aged care appeared to have an international outlook. About $70 \%$ of articles were published in international journals. Ageing and aged care researchers also appeared to draw substantially on research funding, with nearly $50 \%$ of articles citing the main funding source as coming from: state or federal government departments, the ARC, charitable trusts or private donation, non-government organisations, and the NHMRC. The proportion of articles citing research as coming from the main nationally competitive schemes (ARC, APA, NHMRC) was $16.7 \%$.

Previous reviews of Australian social work research have raised concerns about the profession's research capacity (Brough, Wagner, \& Farrell, 2013; Ryan \& Sheehan, 2009), although there is evidence that this is changing. For example, Simpson and Lord (2015) reported that the proportion of research articles published in Australian Social Work increased from 17\% in 2001 to $79 \%$ in 2014. With respect to research on ageing and aged care, it is clear that Australian researchers are contributing to a body of multidisciplinary research knowledge that may assist in promoting the health and wellbeing of older people. Social workers are also engaged in research that seeks to understand service user perspectives and transform policy and service delivery. However, it is also the case that there has been relatively little research specifically on direct social work practice with older people, with limited evidence that research programs are focusing on the evaluation of social work interventions. This limits understanding of the specific disciplinary social work contribution to working with older people, and claims for distinctive disciplinary expertise within a multi-disciplinary field. This could be strengthened by improving the research-practice nexus in social work with older people by engaging in more consistent programme and intervention evaluation. The capacity of social workers to draw on research-based knowledge in their practice is an issue for the whole profession, and strategies that distill and make accessible knowledge for practice (Pope, Rollins, Chaumba, \& Risler, 2011) can be used to advance social work with older people, just as much as in other fields.

Given aged care is the subject of ongoing and substantial policy reform it is important that social work research is strategic, innovative, high quality, and concerned with the intended and unintended outcomes of policy and practice. Social work can make a positive contribution to policy deliberations because of the discipline's capacity to research service users' experience and understand research and practice in the context of social justice issues (Brough et al., 2013). However, in our project there was little evidence that this had occurred in the studies reviewed. In only 16 articles $(14.8 \%)$ was it clear that older people or carers participated in research processes outside of the usual role prescribed to research participants. In just 8 articles was there evidence that older people or carers were directly involved in research design. Only 3 of these articles evidenced considerable user control over the research process potentially demonstrating the influence of humanistic democratic principles or even counter-hegemonic practices (Carey, 2010). It appears that the effective use of inclusive, rights-focused and emancipatory research methods and practices is more present in other fields of social work research, such as with people with disabilities (e.g., Bigby, Frawley, \& Ramcharan, 2014) than in social work research 
on ageing and aged care. Promotion of democratic participation models of older people and carer involvement in research has the potential to provide a platform for service users' voices to be heard within a complex and changing policy environment.

Consequently there appears to be considerable scope for building the capacity of Australian social work research into ageing and aged care. One model that appears to have been successful in Australia is the Emerging Researchers in Ageing (ERA) network (http://www.era.edu.au), which holds an annual conference alongside the Australian Association of Gerontology (AAG) national conference. This network was developed in response to reports that early career gerontology researchers needed additional support and guidance, including forming connections with other emerging researchers, and forming networks with more established researchers to support a long term career in this field (Bartlett, Underwood, \& Peach, 2007). The large proportion of social work authors (65.7\%) who had only published one paper captured in this scoping review may be indicative of a lack of capacity or interest to build longterm careers centred on ageing and aged care research. Thus, linking in prospective social work researchers (particularly postgraduate research students) with the ERA network would be valuable, as would consideration of a stream within this network specifically targeting the needs of social work researchers, including mentoring (Henwood, Bartlett, \& Carroll, 2011). Alternatively an ageing and aged care stream could be introduced into a similar network focusing on emerging researchers in social work. Lessons may be drawn from the evaluation of a training program in ageing research targeting social work faculty in the United States, including having multiple follow-up activities, linking participants with experts in the field, maintaining relationships with participants' employers to ensure ongoing support, and providing the opportunity to have individual consultations (Mehrotra, Townsend, \& Berkman, 2013).

Related to research capacity-building is the overall profile of social work with older people in Australia, and the ongoing concerns about student interest in this area. If the significance and richness of social work with older people were more appreciated by qualifying social work students, then perhaps research careers in ageing and aged care may be easier to stimulate. Questions in the UK about the coverage of ageing content in qualifying curricula (Richards et al., 2014) are also relevant in the Australian context. There is limited attention in the Australian Social Work Education and Accreditation Standards (Australian Association of Social Workers [AASW], 2012) to ageing and aged care, despite other areas of practice or client groups being accorded detailed curriculum guidance. Clearly there is a need to examine the extent to which social work curricula do address issues relating to ageing and aged care, and enable students to acquire the specialist knowledge and skills to engage effectively with older people (Richards et al., 2014). This could then provide a basis for developing innovative strategies to maximise student interest in this area, including increasing students' contact with older people generally and as service users.

\section{Limitations}

In drawing conclusions from this scoping review, it is important to bear in mind a number of limitations. While every effort was made to capture all the publications relating to Australian social work research on ageing and aged care through the systematic search protocols, it is possible that some were missed. Limiting the search to journal articles meant that important research studies reported in books, research reports or the grey literature may have been missed. It is also possible that some Australian research may have been published in non-English language journals, or in journals that were not indexed by the seven databases used. While the review categorised research publications according to their broad methodology, it was beyond the scope of the review to evaluate the quality of these methods. The review also did not evaluate the impact of Australian social work research on outcomes for service users, social work practice or the knowledge base on ageing and aged care. As discussed, we adopted a 
particular approach to identifying social work research - by focusing on the research conducted by social workers - and it is likely that a different definition, such as one focusing on the purpose of social work research, would have resulted in a different sample of articles. Inevitably, whatever boundaries are drawn around the definition of social work research there will be some anomalies.

\section{Conclusion}

Multidisciplinary research into ageing and aged care is important (Coles, Byles, Dow, \& Tavener, 2013), and it is clear that social workers are contributing to building this stock of knowledge in Australia. Social workers are also actively researching older people's experiences and investigating the impacts of social policy and service delivery on the older population. However, as this scoping review has demonstrated, there is relatively little research being conducted specifically on direct social work practice with older people in Australia, and only a few studies that demonstrated the involvement of older people or carers in research design and implementation. This is despite the substantial contribution social workers make in providing services to older Australians and the considerable potential role of social work to help address the impacts of population ageing, policy development and service restructuring. There are also questions about the long-term research capacity of social workers working with older people, with most social work researchers captured in this study having published only one article on ageing and aged care between January 2007 and June 2014. There is a need for investing not only in the research-practice nexus in social work with older people, but also in supporting the research careers of social workers interested in ageing and aged care. Such investment may come from development of social work specific capacity-building exercises, as well as linking social worker researchers to multidisciplinary gerontology endeavours.

\section{Research ethics}

This study comprised an analysis of publicly available literature and thus approval by a formally-constituted ethics committee was not required.

\section{Funding}

No funding was received for completion of this study.I

\section{Acknowledgements}

The authors wish to acknowledge the contribution of Dr Jennifer Osmond in the development of this research.

\section{References}

Arksey, H., \& O’Malley, L. (2005). Scoping studies: Towards a methodological framework. International Journal of Social Research Methodology, 8, 19-32. doi: 10.1080/1364557032000119616

Armstrong, R., Hall, B. J., Doyle, J., \& Waters, E. (2011). 'Scoping the scope' of a Cochrane review. Journal of Public Health, 33, 147-150. doi: 10.1093/pubmed/fdr015

Australian Association of Social Workers (2012). Australian social work education and accreditation standards. Canberra: Author. 
Australian Bureau of Statistics (2009). Future population growth and ageing. Australian Social Trends 4102.0.

Australian Bureau of Statistics (2013). Population projections, Australia 2012 (base) to 2101. 3222.0.

Australian Institute of Health and Welfare (2013). Australia's welfare 2013: The 11th biennial welfare report of the Australian Institute of Health and Welfare (No. Australia's Welfare Series no.11. Cat. no. AUS 174). Canberra: Author.

Bartlett, H., Underwood, M., \& Peach, L. (2007). Building capacity in ageing research: Implications from a survey of emerging researchers in Australia. Australasian Journal on Ageing, 26, 187-193. doi: 10.1111/j.1741-6612.2007.00262.x

Bigby, C., Frawley, P., \& Ramcharan, P. (2014). Conceptualizing inclusive research with people with intellectual disability. Journal of Applied Research in Intellectual Disabilities, 27, 3-12. doi: $10.1111 /$ jar.12083

Brough, M., Wagner, I., \& Farrell, L. (2013). Review of Australian health related social work research 1990-2009. Australian Social Work, 66, 528-539. doi: $10.1080 / 0312407 x .2012 .738236$

Carey, M. (2010). Should I stay or should I go? Practical, ethical and political challenges to "service user" participation within social work research. Qualitative Social Work, 10, 224243. doi: $10.1177 / 1473325010362000$

Carey, M. (2016). Journey's end? From residual service to newer forms of pathology, risk aversion and abandonment in social work with older people. Journal of Social Work, 16, 344-361. doi: 10.1177/1468017315578639

Chapin, R. K., Sellon, A., \& Wendel-Hummell, C. (2015). Integrating education, research, and practice in gerontological social work: Lessons learned from the Reclaiming Joy Peer Support Program. Gerontology \& Geriatrics Education, 36, 242-260. doi: 10.1080/02701960.2015.1009055

Chonody, J. M., \& Wang, D. (2014). Predicting social work students' interest in gerontology: Results from an international sample. Journal of Gerontological Social Work, 57, 773-789. doi: 10.1080/01634372.2014.888605

Coles, T., Byles, J., Dow, B., \& Tavener, M. (2013). Advances in gerontology research and education: Perspectives from the Australian Association of Gerontology. Australasian Journal on Ageing, 32, 40-45. doi: 10.1111/ajag.12095

D’Cruz, H., \& Gillingham, P. (2016). Participatory research ideals and practice experience: Reflections and analysis. Journal of Social Work. Advance online publication. doi: $10.1177 / 1468017316644704$

Duffy, F., \& Healy, J. P. (2011). Social work with older people in a hospital setting. Social Work in Health Care, 50, 109-123. doi: 10.1080/00981389.2010.527786

Fisher, M. (2002). The role of service users in problem formulation and technical aspects of social research. Social Work Education, 21, 305-312. doi: 10.1080/02615470220136885

Henwood, T., Bartlett, H., \& Carroll, M. (2011). Mentoring Australian emerging researchers in aging: Evaluation of a pilot mentoring scheme. Educational Gerontology, 37, 703-714. doi: $10.1080 / 03601271003723594$

Hughes, M., \& Heycox, K. (2006). Knowledge and interest in ageing: a study of final-year social work students. Australasian Journal on Ageing, 25, 94-96. doi: 10.1111/j.17416612.2006.00158.x

Hughes, M., \& Heycox, K. (2010). Older people, ageing and social work: Knowledge for practice. Sydney: Allen \& Unwin.

McCormack, J. T. (2008). Educating social workers for the demographic imperative. Australian Health Review, 32, 400-404. doi: 10.1071/ah080400

McStay, J. (2015). Great expectations: Consumer choice in residential. Australian Ageing Agenda, (July - August), 32-33. Retrieved from 
http://search.informit.com.au.ezproxy.scu.edu.au/documentSummary;dn=480902485618615 ;res=IELHEA

Mehrotra, C., Townsend, A., \& Berkman, B. (2013). Evaluation of a training program in aging research for social work faculty. Educational Gerontology, 39, 787-796. doi: 10.1080/03601277.2012.734155

Mehrotra, C. M., Townsend, A., \& Berkman, B. (2014). A national training program in aging research for social work faculty. Educational Gerontology, 40, 242-247. doi: 10.1080/03601277.2014.852930

Moher, D., Liberati, A., Tetzlaff, J., Altman, D. G., \& The PRISMA Group (2009). Preferred reporting items for systematic reviews and meta-analyses: The PRISMA statement. PLoS Medicine, 6, e1000097. doi: 10.1371/journal.pmed.1000097

Orme, J. (2006). What are we producing knowledge for? JANUS: Finnish Journal of Social Policy and Social Work Research, 14, 196-208. Retrieved from https://pure.strath.ac.uk/portal/en/publications/what-are-we-producing-knowledgefor(54f11209-d7c4-41de-b85e-ad1282a6333e)/export.html

Ozanne, E., Biggs, S., \& Kurowski, W. (2014). Competing frameworks in planning for the aged in the growth corridors of Melbourne. Journal of Aging \& Social Policy, 26, 147-165. doi: 10.1080/08959420.2014.860311

Pham, M. T., Rajić, A., Greig, J. D., Sargeant, J. M., Papadopoulos, A., \& McEwen, S. A. (2014). A scoping review of scoping reviews: Advancing the approach and enhancing the consistency. Research Synthesis Methods, 5, 371-385. doi: 10.1002/jrsm.1123

Pope, N. D., Rollins, L., Chaumba, J., \& Risler, E. (2011). Evidence-based practice knowledge and utilization among social workers. Journal of Evidence-Based Social Work, 8, 349-368. doi: 10.1080/15433710903269149

Raveis, V. H., Gardner, D. S., Berkman, B., \& Harootyan, L. (2010). Linking the NIH Strategic Plan to the research agenda for social workers in health and aging. Journal of Gerontological Social Work, 53, 77-93. doi: 10.1080/01634370903361953

Richards, S., Sullivan, M. P., Tanner, D., Beech, C., Milne. A., Ray, M., ... Lloyd, L. (2013). On the edge of a new frontier: Is gerontological social work in the UK ready to meet twentyfirst-century challenges? British Journal of Social Work, 44, 2307-2324. doi: $10.1093 / \mathrm{bjsw} / \mathrm{bct} 082$

Robertson, M. (2008). Listening: A psychosocial intervention in an end-of-life case of trauma and emotion in the 'space' of a residential care facility. Journal of Social Work in End-OfLife \& Palliative Care, 4, 214-228. doi: 10.1080/15524250902822374

Ryan, M., \& Sheehan, R. (2009). Research articles in Australian Social Work from 1998-2007: A content analysis. Australian Social Work, 62, 525-542. doi: 10.1080/03124070902964616

Simons, K., Shepherd, N., \& Munn, J. (2008). Advancing the evidence base for social work in long-term care: The disconnect between practice and research. Social Work in Health Care, 47, 392-415. doi: 10.1080/00981380802258458

Simpson, G. K., \& Lord, B. (2015). Editorial: Applied research methods. Australian Social Work, 68, 281-283. doi: 10.1080/0312407x.2015.1035363 
7 Databases searched: Cinahl, Scopus, Current Contents, Psychinfo, Social Service Abstracts, Medline and Sociological Abstracts

All items imported into Endnote: 17,494 publications

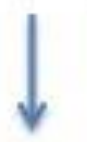

Applied Endnote journal limit strategy "social work" (any field): 2787 publications (duplicates removed)

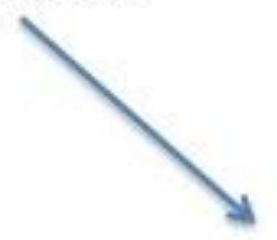

27 Australian Research Centres on Ageing, Welfare and Health surveyed: 7 social work qualified people with research outcomes in ageing or aged care identified

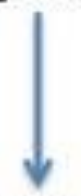

Names of 7 social work qualified researchers searched in 7 Databases: Cinahl, Scopus, Current Contents, Psychinfo, Social Service Abstracts, Medline and Sociological Abstracts: 78 publications (duplicates removed)

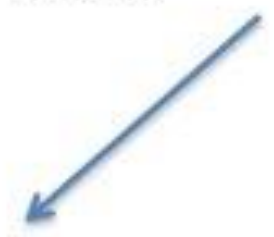

Both sets merged $\&$ duplicates removed. Manual assessment of title, author details and abstract: 143 publications

Manual assessment of full article content: 108 publications 
